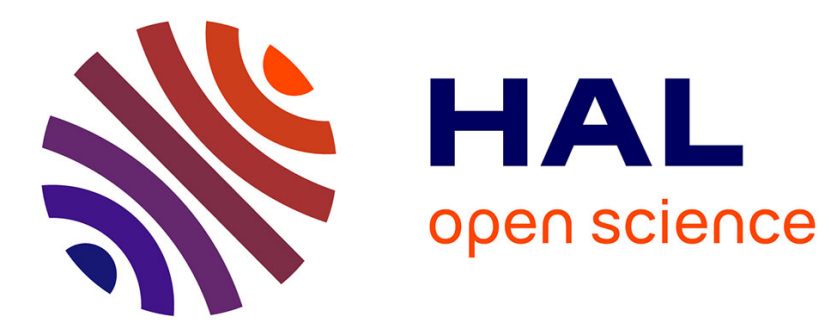

\title{
Self-tuned properties of CuZnO catalysts for hydroxymethylfurfural hydrodeoxygenation towards dimethylfuran production
}

\author{
Magdalena Brzezińska, Nicolas Keller, Agnieszka Ruppert
}

\section{To cite this version:}

Magdalena Brzezińska, Nicolas Keller, Agnieszka Ruppert. Self-tuned properties of CuZnO catalysts for hydroxymethylfurfural hydrodeoxygenation towards dimethylfuran production. Catalysis Science \& Technology, 2020, 10 (3), pp.658-670. 10.1039/C9CY01917K . hal-03004519

\author{
HAL Id: hal-03004519 \\ https://hal.science/hal-03004519
}

Submitted on 9 Dec 2020

HAL is a multi-disciplinary open access archive for the deposit and dissemination of scientific research documents, whether they are published or not. The documents may come from teaching and research institutions in France or abroad, or from public or private research centers.
L'archive ouverte pluridisciplinaire $\mathbf{H A L}$, est destinée au dépôt et à la diffusion de documents scientifiques de niveau recherche, publiés ou non, émanant des établissements d'enseignement et de recherche français ou étrangers, des laboratoires publics ou privés. 


\section{ARTICLE}

\section{Self-tuned properties of CuZnO catalysts for hydroxymethylfurfural hydrodeoxygenation towards dimethylfuran production}

Received 00th January 20xx, Accepted 00th January 20xx DOI: $10.1039 / x 0 x x 00000 x$

\author{
Magdalena Brzezinska, ${ }^{\mathrm{a}, \mathrm{b}}$, Nicolas Keller ${ }^{\mathrm{b}}$ and Agnieszka M. Ruppert ${ }^{*}$
}

\begin{abstract}
5-hydroxymethylfurfural (HMF) is a very valuable platform molecule obtained from biomass. It can be catalytically transformed to many industrially-relevant products of both oxidation and reduction reactions. In this work, we showed that robust CuZnO can be efficient, self-tuned catalyst for the 2,5-dimethylfuran (DMF) (biofuel additive) synthesis. We showed that the CuZnO catalysts can be further activated in the reaction environment and this process depends strongly on the initial catalyst properties and therefore on the catalyst preparation method. Smaller copper particles are more active but more prone for carbon deposit formation. Based on activity tests and extensive characterization, we have concluded that both $\mathrm{Cu}^{\text {n+ }}$ and $\mathrm{Cu}^{\circ}$ sites are necessary for high HMF conversion. While those two sites favor high conversion and high 2,5-bishydroxymethylfuran (BHMF) yield, the in situ formation of Lewis acid sites is proposed to be necessary for achieving high yield to DMF.
\end{abstract}

\section{Introduction}

Fossil fuel depletion puts us in front of a challenge of finding an alternative source of both fuels and chemicals. ${ }^{1}$ Among all the candidates, lignocellulosic biomass seems to be one of the most promising sustainable source of raw carbon material, thanks to its abundance and the lack of competition with food production. Lignocellulosic biomass is therefore considered as a renewable source of platform molecules that have numerous potential applications in future biorefinery, chemicals and materials sectors. ${ }^{2}$ In this frame, 5-hydroxymethylfurfural (HMF) is a very valuable platform molecule, that can be obtained via multi-step process initiated first by the acidic hydrolysis of lignocellulose. Thanks to its high functionalization, with both hydroxyl and carbonyl groups in the structure, HMF can be further catalytically transformed for in fine obtaining many industriallyrelevant products of both oxidation and reduction reactions. ${ }^{3,4}$

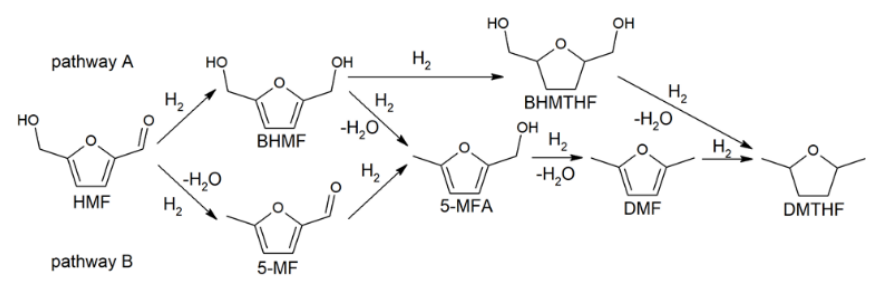

Scheme 1. HMF hydrodeoxygenation reaction pathway

a. Institute of General and Ecological Chemistry, Faculty of Chemistry, tódź University of Technology, ul. Żeromskiego 116, 90-924 Łódź, Poland.

e-mail: agnieszka.ruppert@p.lodz.pl; Fax: +48426313128; Tel: +48426313106

b. Institut de Chimie et Procédés pour l'Energie, l'Environnement et la Santé, ICPEES, CNRS, University of Strasbourg, 25 rue Becquerel, 67087 Strasbourg, France

Electronic Supplementary Information (ESI) available: cell parameters of catalysts, $\mathrm{CU}$ mean particle size during cycling procedure, SEM image and STEM imaging of selected samples, XPS analysis. See DOI: 10.1039/x0xx00000x
Scheme 1 illustrated the HMF hydrodeoxygenation reaction pathway, with in the first step the HMF hydrogenation (pathway A) with the formation of 2,5-bishydroxymethylfuran (BHMF) or its hydrodeoxygenation (pathway $B$ ) with the formation of 5-methylfurfural (5-MF). In the next step, BHMF undergoes hydro-dehydration reaction into 5-methylfurfuryl alcohol (5-MFA), while 5-MFA may also be obtained by hydrogenation of 5-MF. Next, 5-MFA undergoes hydrodehydration with formation of 2,5-dimethylfuran (DMF) which can be further hydrogenated to 2,5-dimethyltetrahydrofuran (DMTHF). DMTHF may also be obtained via the hydrodeoxygenation of 2,5-bishydroxymethyl-tetrahydrofuran (BHMTHF), resulting from the hydrogenation of the $\mathrm{C}=\mathrm{C}$ bonds in $\mathrm{BHMF}$.

Among many valuable HMF-derived chemicals, 2,5-bishydroxymethylfuran (BHMF) and 2,5-dimethylfuran (DMF) gained a lot of interest. While BHMF can be potentially used as a substrate for biopolymer production, as it shows similar properties to crude oil-derived poly(ethylene terephthalate) and can successfully replace it. ${ }^{5,6} \mathrm{DMF}$ is thought to be used as a biofuel (notably as cold-start fuel) 7 or as a biofuel additive without any change in the engine construction, thanks to physicochemical properties similar to those of gasoline and high octane number. ${ }^{8}$

Most of the works is mainly devoted to the synthesis of DMF through HMF hydrodeoxygenation, that was widely achieved with the use of catalysts based on noble metals such as Pd, Pt, $\mathrm{Rh}$ and $\mathrm{Ru} .{ }^{9,10}$ However, the restrictive use of additional acids such as $\mathrm{H}_{2} \mathrm{SO}_{4}, \mathrm{HCl}$ or acetic acid for promoting the dehydration step during the HMF conversion and the high price of noble metals are clearly the driving force behind the search for active, selective and stable noble metal-free catalysts for HMF conversion. Up to now, catalytic systems based on $\mathrm{Ni}, \mathrm{Co}$, Fe and $\mathrm{Cu}$ were mainly investigated in the mentioned process ${ }^{9,10,12-14}$ 
and it was shown that non-noble metals can be as active and selective as their noble metal counterparts, while being more sustainable and allowing an easier selectivity control. Lilga et al. studied cobalt-based catalysts and evidenced that Raney Co and $\mathrm{Co} / \mathrm{SiO}_{2}$ allowed similar performance than the $\mathrm{Pt} / \mathrm{Al}_{2} \mathrm{O}_{3}$ catalyst to be achieved under similar reaction conditions, with the absence of any DMF production and BHMF as the main product obtained. ${ }^{15}$ The Palkovits's group recently highlighted that higher HMF conversions were achieved on carbon supported nickel catalysts using ether solvents such as THF or MTHF when compared to alcoholic solvents; however the catalysts suffered from deactivation, while very high hydrogen pressure of 100 bar and high nickel loadings were unfortunately necessary to reach high DMF yield. ${ }^{16}$ Although alumina supported nickel catalyst could substitute its palladium-based counterpart when water was used as solvent - since both catalysts exhibited similar activity and selectivity profiles, Duarte et al. indicated that they both suffered from the absence of any DMF formation, while hydrogenation and dehydration products of HMF were observed like 5-MFA and furfuryl alcohol. The authors also evidenced that high selectivity to 5-MF and 5-MFA intermediates was observed on the copper-based counterpart catalyst, although the catalyst suffered from a moderate activity. ${ }^{17}$

As far as copper catalysts are concerned, copper chromite an industrial hydrogenation catalyst - was one of the first catalysts studied in the HMF hydrodeoxygenation reaction thanks to the pioneering work by Dumesic group, that developed a process in which a sugar solution was directly converted into DMF with high selectivity (67\%). Although the deactivation with time observed for the catalyst was overcome by performing a regeneration under hydrogen flow, both the high $\mathrm{Cu}$ loading and the high toxicity of chromium remained highly detrimental to the process and strategies for designing suitable catalysts still need to be implemented. ${ }^{18}$ Due to the high affinity of $\mathrm{Cu}$ for the hydrogenation of carbonyl groups, copper-based catalysts are considered as promising systems for the HMF hydrodeoxygenation reaction. ${ }^{19}$ In addition the support itself needs to exhibit appropriate acidity in order to obtain DMF with high selectivity, and many studies highlighted the key-role played by the support in the Cu catalyst behavior. Alumina was investigated as $\mathrm{Cu}$ catalyst support due to its high acidity. However, although the $\mathrm{Cu} / \mathrm{Al}_{2} \mathrm{O}_{3}$ catalyst allowed DMF to be obtained as the main reaction product after $140 \mathrm{~min}$ of test conducted at $175^{\circ} \mathrm{C}$ under 20.7 bar of $\mathrm{H}_{2}$, the catalyst suffered from deactivation, that resulted from the inhibition of the catalyst active sites through water molecule adsorption. ${ }^{20}$

The Luque's group investigated Al-SBA15 aluminosilicate materials as $\mathrm{Cu}$ catalyst support and reported partial HMF dehydration into 5-methyl-2-furfuryl alcohol with a $60 \%$ selectivity for short time reactions, due to the presence of acid centers and the use of microwave irradiation. Although higher selectivity was achieved through the incorporation of $\mathrm{Zn}$ into the structure of the support, that lowered the overall acidity of the system which inhibited proceeding side reactions, only traces of DMF were observed in the reaction mixture. ${ }^{21}$ Zhang et al. recently compared the behavior of highly loaded $\mathrm{Cu}$ catalysts $(20 \%)$ supported on different oxides $\left(\mathrm{Al}_{2} \mathrm{O}_{3}, \mathrm{ZrO}_{2}\right.$
$\mathrm{CeO}_{2}, \mathrm{ZnO}$ ). On one hand, both $\mathrm{Al}_{2} \mathrm{O}_{3}$ and $\mathrm{ZnO}$ supports allowed the highest DMF yields to be obtained, as a result of the formation of the smallest $\mathrm{Cu}$ crystallite size among all tested supports. ${ }^{22}$ On another hand, a high acidity and a better utilization of the internal hydrogen generated from methanol in this study were reported as important factors in the case of $\mathrm{Cu} / \mathrm{Al}_{2} \mathrm{O}_{3}$ and $\mathrm{Cu} / \mathrm{ZnO}$ catalysts, respectively. However, the reaction required to operate at relatively high temperature $\left(240^{\circ} \mathrm{C}\right)$ and for long reaction times $(>6 \mathrm{~h})$. Furthermore, the catalysts suffered from a poor stability with the highest $\mathrm{Cu}$ leaching being obtained for the $\mathrm{ZnO}$ supported catalyst.

The activity of different commercially available copperbased nanopowders ( $\mathrm{Cu}, \mathrm{CuO}, \mathrm{CuFe}_{2} \mathrm{O}_{4}, \mathrm{CuZnFe}_{2} \mathrm{O}_{4}, \mathrm{CuZn}$ ) was investigated by the Bart's group, among which the CuZn catalyst showed the highest activity and selectivity towards DMF when the reaction was performed in ethanol at $220^{\circ} \mathrm{C}$ under 30 bar $\mathrm{H}_{2}$ for $6 \mathrm{~h} .{ }^{23}$ This good catalytic performance was explained by the simultaneous presence of $\mathrm{Zn}^{2+}$ cations which were identified as dehydration centers, and of $\mathrm{Cu}^{0}$ acting as $\mathrm{HMF}$ hydrogenation centers. Further, relatively small-size CuZn particle for a nano composite catalyst $(<150 \mathrm{~nm})$ was beneficial for obtaining high DMF yield. Although the catalyst exhibited a good stability with time in the reaction mixture, with no evidenced leaching despite the high Cu loading, the reaction selectivity was strongly reduced to achieve a level as low as $17 \%$ for the fourth cycle. In agreement with the dual nature of the CuZn catalyst surface developed in Bart's work, Zhu et al. optimized the Cu content of the catalyst at 54 wt.\% of $\mathrm{Cu}$ for achieving full HMF conversion with high selectivity towards DMF when the reaction was performed at $220^{\circ} \mathrm{C}$ under 15 bar of $\mathrm{H}_{2}$ for longer than 5 h. ${ }^{19}$ However, despite the use of a very high copper content, the CuZn catalysts turned out to be completely unstable as a function of test cycling and were consequently suffering from a low HMF conversion of $30 \%$ at a $10 \%$ selectivity to DMF after one single run.

The aim of this work is to investigate the key-factors responsible for high activity of CuZnO catalysts in the HMF hydrodeoxygenation reaction, by studying the influence of the preparation method of the catalysts on its catalytic properties.

A photoassisted method at room temperature was compared to a classical wet impregnation one with final temperature treatment. We showed that the choice of the preparation method and the chemical state of the $\mathrm{Cu}$ nanoparticles strongly influenced the catalyst activity, and allowed the HMF hydrodeoxygenation selectivity to be tuned. Performing an oxidative treatment as intrinsic part of the catalyst cycling protocol was reported to be crucial for both the performance and the stability of the catalysts.

\section{Experimental}

\section{Support synthesis}

$\mathrm{ZnO}$ was synthesized using precipitation synthesis method in which $1.75 \mathrm{~g}$ of zinc(II) acetate dihydrate $\left(\mathrm{Zn}(\mathrm{OAc})_{2} \cdot 2 \mathrm{H}_{2} \mathrm{O}\right.$, SigmaAldrich, Saint Louis, MO, USA, ACS reagent, $\geq 98 \%$ ) and $0.84 \mathrm{~g}$ of sodium carbonate $\left(\mathrm{Na}_{2} \mathrm{CO}_{3}\right.$, Sigma-Aldrich, $\left.99.5 \%\right)$ were 
dissolved under stirring in $50 \mathrm{~mL}$ of distilled water, respectively. Both aqueous solutions were mixed, and the obtained precipitate was aged at room temperature in the mother liquor for $24 \mathrm{~h}$ under continuous stirring. The suspension was further centrifuged for $30 \mathrm{~min}$ at $3500 \mathrm{rpm}$, and finally washed and filtrated under vacuum with distilled water. The resulting powder was dried at $100^{\circ} \mathrm{C}$ for $12 \mathrm{~h}$ and subsequently calcined at a temperature of $300^{\circ} \mathrm{C}$ for $2 \mathrm{~h}$ with a $10^{\circ} \mathrm{C} / \mathrm{min}$ heating rate.

\section{Catalyst preparation}

CuZno catalyst prepared via wet impregnation method. The catalyst was prepared with a $10 \mathrm{wt} . \%$ metal content using an aqueous solution of $\mathrm{Cu}\left(\mathrm{NO}_{3}\right)_{2}$ (Chempur, pure) with a concentration of $5000 \mathrm{mg} / \mathrm{l}$. The $\mathrm{ZnO}$ support was impregnated by the metallic salt solution and the catalyst suspension was aged for $24 \mathrm{~h}$ at room temperature, before the excess of solvent was evaporated at $100^{\circ} \mathrm{C}$ using a magnetic stirrer. The sample was dried at $100^{\circ} \mathrm{C}$ for $1 \mathrm{~h}$, before to be calcined in flowing air at $300^{\circ} \mathrm{C}$ for $2 \mathrm{~h}$ (heating rate of $10^{\circ} \mathrm{C} / \mathrm{min}$ ). After cooling down to room temperature, the catalyst was further reduced in hydrogen flow $(60 \mathrm{~mL} / \mathrm{min})$ for $1 \mathrm{~h}$ at a temperature within the $200-550^{\circ} \mathrm{C}$ range with a heating rate of $10^{\circ} \mathrm{C} / \mathrm{min}$. The non-reduced and reduced catalysts were labeled as $\mathrm{CuZnO}(\mathrm{I})$ and $\mathrm{CuZnO}(\mathrm{I}) \mathrm{T}_{\text {red }}$, respectively, depending on the reduction temperature.

Photon-assisted preparation of CuZnO catalysts. The catalyst was performed by irradiating with solar light an aqueous suspension of the $\mathrm{ZnO}$ support containing $\mathrm{Cu}\left(\mathrm{NO}_{3}\right)_{2}$ as copper precursor. The irradiation was provided by an Atlas Suntest XLS+ reaction chamber equipped with a Xenon arc lamp adjusted to a $500 \mathrm{~W} / \mathrm{m}^{2}$ irradiance (with a $30 \mathrm{~W} / \mathrm{m}^{2}$ UV-A content) (320-800 $\mathrm{nm}$ wavelength range, ICH Q1B guidelines). The amount of copper precursor used was adjusted to have a Cu content of 10 wt \% in the catalyst.

The dissolution of $38 \mathrm{mg}$ of $\mathrm{Cu}(\mathrm{II})$ nitrate trihydrate (SigmaAldrich, p.a) was performed in water at room temperature, before $90 \mathrm{mg}$ of $\mathrm{ZnO}$ was dispersed under stirring in $100 \mathrm{ml}$ of copper solution in a beaker-type glass reactor at a $0.38 \mathrm{~g} / \mathrm{l}$ concentration. Prior to irradiation, the suspension was stirred in the dark for $30 \mathrm{~min}$ at $60^{\circ} \mathrm{C}$ to ensure the establishment of the adsorption/desorption equilibrium, before the photon-assisted synthesis was performed under stirring under solar light for $2 \mathrm{~h}$. The synthesis was monitored by UV-vis spectrophotometry by following the disappearance of the absorption peak at $\lambda=800$ $\mathrm{nm}$. The catalyst was washed and filtrated under vacuum several times with distilled water, and finally dried at $100^{\circ} \mathrm{C}$ for $1 \mathrm{~h}$. The as-prepared sample was then labelled as $\mathrm{CuZnO}(\mathrm{P})$.

\section{Catalytic test}

5-hydroxymethylfurfural hydrodeoxygenation. In a typical 5hydroxymethylfurfural hydrodeoxygenation experiment, $1 \mathrm{~g}$ of $\mathrm{HMF}$, $0.3 \mathrm{~g}$ of a catalyst and $30 \mathrm{ml}$ of dioxane were combined in a $60 \mathrm{ml}$ Hastelloy autoclave. The reactor was pressurized with hydrogen to $30 \mathrm{bar}$ and the temperature was maintained at $220^{\circ} \mathrm{C}$ for $5 \mathrm{~h}$. After the reaction time, the autoclave was cooled down and the remaining pressure was released. The obtained reaction mixture was then centrifuged to separate the catalyst from the solution. The products were further analysed with an Agilent 7820A GC instrument equipped with a flame ionization detector and a CP-Wax 52 CB capillary column.

The activity of the catalysts were expressed in terms of HMF conversion and of reaction yield to given products, and were calculated as follows:

$$
\begin{gathered}
\text { Conversion }=\frac{n_{H M F_{i}}-n_{H M F_{r}}}{n_{H M F_{i}}} \cdot 100 \% \\
\text { Yield }_{p}=\frac{n_{p}}{n_{H M F_{i}}} \cdot 100 \%
\end{gathered}
$$

where $n(\mathrm{HMF})_{i}$ and $\mathrm{n}(\mathrm{HMF})_{r}$ are the number of moles of $\mathrm{HMF}$ molecules, before and after test, respectively, and $n(P)$ is the number of moles of a given product within the reaction mixture.

For assessing the catalyst recycling behavior, the catalyst was recovered from the reaction media by centrifugation, with a subsequent washing with deionized water and final drying step.

\section{Catalyst characterization}

$\mathrm{X}$-ray diffraction (XRD) measurements were collected using a D8 Advance Bruker diffractometer operating in a $\Theta / \Theta$ mode. The $X-$ ray source was a $\mathrm{Cu}$ long fine focus $\mathrm{X}$-ray diffraction tube operating at $40 \mathrm{kV}$ and $40 \mathrm{~mA}$, with a $\mathrm{K}_{\alpha 1}$ radiation at $\lambda=1.5406$ $\AA$. Data were collected in the $20-85^{\circ} 2 \theta$ range with a $0.0263^{\circ}$ scan step and a $0.6 \mathrm{~s}$ step time. Some patterns have been investigated by Rietveld refinement with the Fullprof software for which the modified Thompson-Cox-Hasting function was chosen to generate the line shape of the diffraction peaks. Instrumental broadening has been previously determined by measuring the scattering from corundum (NIST standard SRM 1976b). ${ }^{24,25}$

Temperature-programmed reduction (TPR) was performed on AMI1 system from Altamira Instruments, USA, equipped with a thermal conductivity detector and was used for examining the reducibility of catalysts. All the catalysts prepared through the wet impregnation method were calcined at $300^{\circ} \mathrm{C}$ (with a $10^{\circ} \mathrm{C} / \mathrm{min}$ heating rate) for $30 \mathrm{~min}$ in a mixture of $2 \mathrm{vol} . \% \mathrm{O}_{2}$ and 98 vol.\% Ar at a space velocity $\mathrm{W} / \mathrm{F}=1.11 \times 10^{-5} \mathrm{~g} / \mathrm{h} \cdot \mathrm{cm}^{3}$, before the TPR profiles were recorded from $35^{\circ} \mathrm{C}$ up to $800^{\circ} \mathrm{C}$, with a heating rate of $7^{\circ} \mathrm{C} / \mathrm{min}$, using a mixture of 5 vol.\% $\mathrm{H}_{2}$ and 95 vol.\% $\mathrm{Ar}$ at a similar space velocity.

Scanning electron microscopy (SEM) was performed in secondary electron mode on a JEOL JSM-6700 F FEG microscope.

Transmission electron microscopy (TEM) was performed using a JEOL $2100 \mathrm{~F}$ with a point resolution of $0.2 \mathrm{~nm}$. A Mo grid was used for performing EDS analysis of $\mathrm{Cu}-\mathrm{ZnO}$ samples. The interplanar spacings were calculated using ImageJ software.

Secondary ion mass spectra were recorded with a time-offlight secondary ion mass spectrometer (ToF-SIMS IV) manufactured by ION-TOF GmbH, Germany, equipped with a $25 \mathrm{kV}$ pulsed $\mathrm{Bi}^{3+}$ primary ion gun working in the static mode. 
The measurements were performed in the static mode. The samples were pressed into pellets and then fixed to the sample holder by double-sided tape. The analyzed area of the sample surface was $500 \mu \mathrm{m} \times 500 \mu \mathrm{m}$. During analysis, a pulsed lowenergy electron flood gun was used for charge neutralization. The experiments were repeated three times for each sample.

Acetone-adsorbed FTIR measurements were carried out with Nicolet 6700 FTIR spectrometer equipped with MCT detector made by Thermo Scientific, using DRIFT cell. Before measurement, the samples were treated following the same procedure used to prepare the catalysts. After cooling to $40^{\circ} \mathrm{C}$ in Ar flow, acetone sorption was first performed for $20 \mathrm{~min}$ and the chamber was further purged with Ar flow for 20 min to get rid of gaseous acetone. All spectra were recorded with a time interval of $2 \mathrm{~min}$ in a wavenumber range of $1800-1600 \mathrm{~cm}^{-1}$, with a scan number of 64 , and a spectral resolution set at $4 \mathrm{~cm}^{-1}$, and using a $20 \mathrm{ml} / \mathrm{min}$ gas flow.

X-ray Photoelectron Spectroscopy (XPS) characterization was performed on a ThermoVGMultilabESCA3000 spectrometer ( $\mathrm{Al} \mathrm{K} \alpha$ anode at $\mathrm{h} \lambda=1486.6 \mathrm{eV}$ ). The energy shift due to electrostatic charging was subtracted using the adventious $\mathrm{sp}^{2}$ carbon C1s band at $284.6 \mathrm{eV}$. Contributions with Doniach-Sunjic shape ${ }^{26}$ and a 'S-shaped' Shirley type background ${ }^{27}$ were used.

Measurements of $\mathrm{Cu}$ and $\mathrm{Zn}$ content in the postreaction mixture were performed with Flame Atomic Absorption Spectrometry (FAAS) using Unicam Solaar M6 Atomic Absorption spectrometer.

\section{Results}

\section{Catalytic activity}

Influence of pretreatment. Table 1 shows the influence of the reduction pretreatment conditions on the performances of the CuZnO catalysts prepared via the impregnation method. The $\mathrm{CuZnO}(\mathrm{I})$ catalyst pre-reduced at the high temperature of $550^{\circ} \mathrm{C}$ exhibited a marginal HMF conversion.

Interestingly by lowering the reduction temperature from $550^{\circ} \mathrm{C}$ to $200^{\circ} \mathrm{C}$, the $\mathrm{HMF}$ conversion gradually increases up to $41 \%$, accompanied by a slight increase in the BHMF selectivity. The non-reduced $\mathrm{CuZnO}(\mathrm{I})$ catalyst allowed to reach almost full HMF conversion (99\%), together with a high selectivity to BHMF. As a result, the highest yield to BHMF of $93 \%$ was obtained on the oxidized $\mathrm{CuZnO}(\mathrm{I})$ catalyst.

Those observations are in contrast with the literature concerning $\mathrm{Cu}$ catalysts supported on various oxides such as $\mathrm{Al}_{2} \mathrm{O}_{3}, \mathrm{CeO}_{2}, \mathrm{TiO}_{2}$ or $\mathrm{ZnO}$ used for HMF conversion, for which a pre-reduction step at high temperature is usually required. ${ }^{19,20,22,28,29}$

Interestingly, the CuZnO catalyst without any pre-reduction treatment was more active than the $\mathrm{Cu} / \mathrm{Al}_{2} \mathrm{O}_{3}$ catalyst, that is actually considered as the reference benchmark catalyst, ${ }^{22}$ and that showed a conversion as low as $21 \%$ with only $15 \%$ yield to $\mathrm{BHMF}$ in our reaction conditions.
Table 1 Influence of the reduction pretreatment conditions on the activity of CuZnO catalysts in HMF hydrodeoxygenation

\begin{tabular}{|c|c|c|c|c|c|c|c|}
\hline \multirow[t]{2}{*}{ Catalyst } & \multirow{2}{*}{$\begin{array}{c}\text { HMF conv. } \\
{[\%]}\end{array}$} & \multicolumn{6}{|c|}{ Product yield [\%] } \\
\hline & & $5-\mathrm{MF}$ & BHMF & 5-MFA & DMF & BHMTHF & DMTHF \\
\hline $\begin{array}{l}\mathrm{CuZnO}(\mathrm{I}) \\
550\end{array}$ & 4 & 1 & 2 & 0 & 0 & 0 & 0 \\
\hline $\begin{array}{l}\text { CuZnO(I) } \\
400\end{array}$ & 12 & 2 & 6 & 0 & 0 & 0 & 0 \\
\hline $\begin{array}{l}\text { CuZnO(I) } \\
300\end{array}$ & 16 & 1 & 7 & 0 & 0 & 0 & 0 \\
\hline $\begin{array}{l}\mathrm{CuZnO}(\mathrm{I}) \\
200\end{array}$ & 41 & 2 & 36 & 1 & 0 & 0 & 0 \\
\hline CuZnO(I) & 99 & 2 & 93 & 2 & 0 & 0 & 0 \\
\hline $\mathrm{Cu} / \mathrm{Al}_{2} \mathrm{O}_{3}{ }^{\mathrm{a}}$ & 21 & 15 & 0 & 1 & 5 & 0 & 0 \\
\hline
\end{tabular}

Reaction conditions: $220^{\circ} \mathrm{C} ; 5 \mathrm{~h} ; 0.3 \mathrm{~g}$ of catalyst; $1 \mathrm{~g}$ of HMF; $30 \mathrm{ml}$ of dioxane; 30 bar of hydrogen. $(*)$ Some by-products in small amounts were detected but not identified. In addition to the accuracy of the measurements at low conversion, this can explain the slight mismatch in the closure of the carbon balance.

${ }^{a} \mathrm{~A}$ reference $\mathrm{Cu} / \mathrm{Al}_{2} \mathrm{O}_{3}$ benchmark catalyst was prepared via wet impregnation with a $10 \mathrm{wt} . \%$ metal content using an aqueous solution of $\mathrm{Cu}\left(\mathrm{NO}_{3}\right)_{2}$. The $\gamma$ $\mathrm{Al}_{2} \mathrm{O}_{3}$ (Fluka) support was impregnated by the metallic salt solution and the catalyst suspension was aged for $24 \mathrm{~h}$ at room temperature, before the excess of solvent was evaporated using rotary evaporator. The sample was dried at $100^{\circ} \mathrm{C}$ for $1 \mathrm{~h}$, before to be calcined in flowing air at $300^{\circ} \mathrm{C}$ for $2 \mathrm{~h}$. After cooling down to room temperature, the catalyst was further reduced in hydrogen flow for $1 \mathrm{~h}$ at $300^{\circ} \mathrm{C}$.

Influence of reaction time. The activity profile was influenced by the reaction time for the CuZnO(P) catalyst (Table 2). Although a high HMF conversion of $93 \%$ was reached already for $1 \mathrm{~h}$ of reaction, the DMF yield remained only moderate at $48 \%$. Extending the reaction time allowed to reach a much higher DMF yield of nearly $80 \%$, giving traces of intermediate reaction products like BHMF and 5-MFA and a very low yield to further $\mathrm{C}=\mathrm{C}$ hydrogenation product DMTHF (9\%).

The situation was fully different in the case of the $\mathrm{CuZnO}(\mathrm{I})$ catalyst. Already almost full conversion was reached after only $0.5 \mathrm{~h}$ of reaction giving a full selectivity to BHMF. BHMF is obtained via $\mathrm{C}=\mathrm{O}$ bond hydrogenation from $\mathrm{HMF}$ and, although it is an intermediate product in the DMF production, the reaction selectivity to $\mathrm{BHMF}$ remained however constant for the $5 \mathrm{~h}$ of the reaction. This contrasts with the $\mathrm{CuZnO}(\mathrm{P})$ catalyst, for which both the $\mathrm{C}=\mathrm{O}$ hydrogenation and the subsequent $\mathrm{C}-\mathrm{O}$ hydrogenolysis occurred, leading to the conversion of BHMF to MFA and DMF. 
Table 2 Influence of the reaction time and catalyst preparation method on the activity of CuZnO catalysts in HMF hydrodeoxygenation

\begin{tabular}{|c|c|c|c|c|c|c|c|c|}
\hline \multirow[t]{2}{*}{ Catalyst } & \multirow{2}{*}{$\begin{array}{c}\text { Time } \\
{[\mathrm{h}]}\end{array}$} & \multirow{2}{*}{$\begin{array}{c}\text { HMF } \\
\text { conv. } \\
{[\%]}\end{array}$} & \multicolumn{6}{|c|}{ Product yield [\%] } \\
\hline & & & 5-MF & BHMF & 5-MFA & DMF & BHMTHF & DMTHF \\
\hline \multirow[t]{2}{*}{ CuZnO(P) } & 1 & 93 & 1 & 5 & 31 & 48 & 2 & 3 \\
\hline & 5 & 100 & 0 & 5 & 6 & 79 & 1 & 9 \\
\hline \multirow[t]{3}{*}{ CuZnO(I) } & 0.5 & 98 & 4 & 93 & 1 & 0 & 0 & 0 \\
\hline & 1 & 99 & 5 & 91 & 3 & 0 & 0 & 0 \\
\hline & 5 & 99 & 2 & 93 & 2 & 0 & 0 & 0 \\
\hline
\end{tabular}

Reaction conditions: $220^{\circ} \mathrm{C} ; 0.3 \mathrm{~g}$ of catalyst; $1 \mathrm{~g}$ of HMF; $30 \mathrm{ml}$ of dioxane; $30 \mathrm{bar}$ of hydrogen.

Recycling of CuZnO catalysts. Taking into account the influence of the reduction pretreatment on the $\mathrm{CuZnO}(\mathrm{I})$ catalyst performances and the reductive nature of the reaction media, it was worth investigating the cycling behavior of the studied CuZnO catalysts (Table 3). First, the direct reuse of the $\mathrm{CuZnO}(\mathrm{I})$ catalyst led to a drastic drop of the activity, almost no HMF conversion (6\%) being observed for the second test. However, when the catalyst was additionally calcined at $300^{\circ} \mathrm{C}$ after the first test, a high HMF conversion was maintained at $95 \%$, while a change in the product distribution was observed, with a decrease in the BHMF yield from $91 \%$ to $31 \%$ together with an increase in the DMF yield from $0 \%$ to $34 \%$. This catalyst change with the increase in the final product of the HMF hydrodeoxygenation reaction may indicate that activation of the catalyst occurred. This activity trend was amplified when performing further consecutive cycling with intermediate oxidation step, with the maintain of a HMF conversion within the $96-100 \%$ range. At the 3rd cycle, a further change in the product distribution was noted, with a complete disappearance of the BHMF product and a strong increase in the DMF yield till a stable level around $80 \% \pm 5 \%$ for several test cycles.

In order to investigate the processes occurring during the cycling procedure, the $\mathrm{CuZnO}(\mathrm{I})$ catalyst was firstly reduced under hydrogen at $300^{\circ} \mathrm{C}$ for activating the CuZnO catalysts, and subsequently oxidized in similar conditions than those used in the cycling tests. The results obtained on the $\mathrm{CuZnO}(\mathrm{I})$-(red)(ox) catalyst showed that only a slight activation occurred, what indicates that other factors plays a key role in the activation of $\mathrm{CuZnO}(\mathrm{I})$ catalysts during the cycling tests.

When it comes to the CuZnO(P) catalyst, it displayed a very high activity with full HMF conversion and DMF as the main hydrodeoxygenation product with a DMF yield of $79 \%$. Similarly as in the case of the CuZnO(I) catalyst, a direct reuse of the CuZnO(P) catalyst resulted in a decrease in the activity, but in a less pronounced way, with the maintain of a HMF conversion of $90 \%$, while the DMF yield decreased down to $43 \%$ and the BHMF yield increased to $26 \%$. Performing an intermediate calcination at $300^{\circ} \mathrm{C}$ after test allowed a total HMF conversion to be achieved for several cycles, with a high DMF yields of $92 \%$ and $94 \%$. This activity dropped only with the 4th reuse giving BHMF and DMF as main reaction products with yields of $47 \%$ and $41 \%$, respectively.

\section{Characterization of fresh CuZnO catalysts}

The XRD patterns of the bare ZnO support and of the CuZnO catalysts prepared through the photon-assisted method and the wet impregnation method with different reduction pretreatments are shown in Figure 1, and the mean crystallite size of both the copper containing phases and the $\mathrm{ZnO}$ support are shown in Table 4. They displayed the diffraction peaks characteristic of $\mathrm{ZnO}$ crystallized in the hexagonal wurtzite structure and corresponding to the diffraction of the (100), (002), (101), (102), (110), and (103) planes for the most intense peaks (P63mc space group, JCPDS 00-036-1451). ${ }^{30}$ In addition to the reflexes from the ZnO support, the XRD patterns of both $\mathrm{CuZnO}(\mathrm{P})$ and $\mathrm{CuZnO}(\mathrm{I})$ catalysts exhibited the diffraction peaks attributed to the (002), (111), (-202), (020), (202), (-113), (-222) and (222) planes of monoclinic Cu(II)O nanoparticles (JCPDS Card 01-089-5895). While the as-synthesized ZnO support had a mean crystallite size of $10 \mathrm{~nm}$, the implementation of both preparation methods led to an increase in the mean crystallite size of the $\mathrm{ZnO}$ support to $20 \mathrm{~nm}$ for the CuZnO(P) catalyst, and in a larger extent to $42 \mathrm{~nm}$ for the CuZnO(I) counterpart. As a result, $\mathrm{CuZnO}(\mathrm{I})$ and $\mathrm{CuZnO}(\mathrm{P})$ catalysts had a specific surface area of $25 \mathrm{~m}^{2} / \mathrm{g}$ and $33 \mathrm{~m}^{2} / \mathrm{g}$, respectively, while the bare support exhibited a surface area of $68 \mathrm{~m}^{2} / \mathrm{g}$.

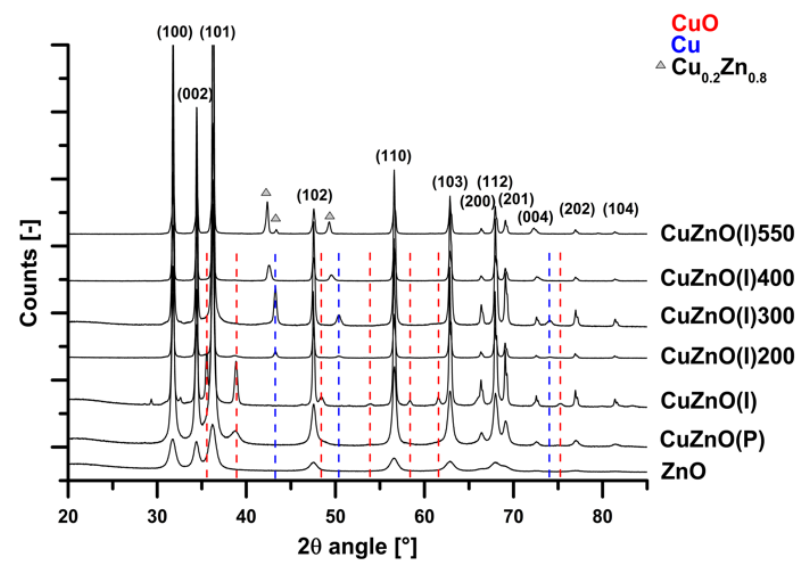

Figure 1. X-Ray Diffraction patterns of the $\mathrm{ZnO}$ support, the $\mathrm{CuZnO}(\mathrm{P})$ catalyst and the $\mathrm{CuZnO}(\mathrm{I})$ catalyst with different reduction pretreatments. The crystallographic planes indicated correspond to the diffraction planes of the $\mathrm{ZnO}$ support.

For both freshly prepared catalysts, a mean CuO crystallite size of $10 \mathrm{~nm}$ was observed for CuZnO(P), whereas a significantly larger mean size of $23 \mathrm{~nm}$ was obtained for $\mathrm{CuZnO}(\mathrm{I})$, as a result of the final calcination step of the catalyst at $300^{\circ} \mathrm{C}$ with exothermic decomposition of the precursor salt. Independently of the preparation method, the CuZnO catalyst can be considered as a CuO-ZnO composite catalyst, since the $\mathrm{CuO}$ 
Table 3 Activity and test-cycling behavior in HMF hydrodeoxygenation of CuZnO catalysts.

\begin{tabular}{|c|c|c|c|c|c|c|c|}
\hline \multirow[b]{2}{*}{ Catalyst } & \multirow[t]{2}{*}{ HMF conv. [\%] } & \multicolumn{6}{|c|}{ Product yield [\%] } \\
\hline & & $5-\mathrm{MF}$ & BHMF & 5-MFA & DMF & BHMTHF & DMTHF \\
\hline CuZnO(I) & 99 & 2 & 91 & 2 & 0 & 0 & 0 \\
\hline $\mathrm{CuZnO}(\mathrm{I})-\mathrm{r} 2$ & 6 & 3 & 0 & 3 & 0 & 0 & 0 \\
\hline $\mathrm{CuZnO}(\mathrm{I})-\mathrm{r} 2(\mathrm{ox})$ & 95 & 7 & 31 & 7 & 34 & 8 & 1 \\
\hline CuZnO(I)-r3(ox) & 100 & 0 & 0 & 0 & 85 & 0 & 15 \\
\hline CuZnO(I)-r4(ox) & 96 & 3 & 11 & 5 & 72 & 0 & 4 \\
\hline CuZnO(I)-r5(ox) & 99 & 2 & 9 & 4 & 77 & 2 & 6 \\
\hline $\mathrm{CuZnO}(\mathrm{I})-(\mathrm{red})(\mathrm{ox})^{\mathrm{a}}$ & 99 & 5 & 81 & 10 & 2 & 1 & 0 \\
\hline $\mathrm{CuZnO}(\mathrm{P})$ & 100 & 0 & 5 & 6 & 79 & 1 & 9 \\
\hline CuZnO(P)-r2 & 90 & 7 & 26 & 10 & 43 & 1 & 4 \\
\hline $\mathrm{CuZnO}(\mathrm{P})-\mathrm{r} 2(\mathrm{ox})$ & 100 & 0 & 0 & 1 & 94 & 0 & 5 \\
\hline CuZnO(P)-r3(ox) & 100 & 1 & 0 & 3 & 92 & 0 & 4 \\
\hline CuZnO(P)-r4(ox) & 100 & 2 & 47 & 9 & 41 & 1 & 0 \\
\hline CuZnO(P)-r5(ox) & 93 & 5 & 47 & 12 & 42 & 0 & 1 \\
\hline
\end{tabular}

Reaction conditions: $220^{\circ} \mathrm{C} ; 5 \mathrm{~h} ; 0.3 \mathrm{~g}$ of catalyst; $1 \mathrm{~g}$ of $\mathrm{HMF} ; 30 \mathrm{ml}$ of dioxane; 30 bar of hydrogen. Nomenclature: eg. the CuZnO(I)-r2 and $\mathrm{CuZnO}(\mathrm{I})-\mathrm{r} 2$ (ox) catalysts corresponds to the $2^{\text {nd }}$ test of the $\mathrm{CuZnO}(\mathrm{I})$ catalyst without and with an intermediate oxidation treatment at $300^{\circ} \mathrm{C}$, respectively; ${ }^{\text {a }} \mathrm{CuZnO}(\mathrm{I})-$ (red)(ox) catalyst corresponds to the $1^{\text {st }}$ test of the $\mathrm{CuZnO}(\mathrm{I})$ catalyst after a reduction treatment under hydrogen at $300^{\circ} \mathrm{C}$ followed by an oxidation treatment at $300^{\circ} \mathrm{C}$.

crystallites do not exhibit significantly smaller mean sizes than the $\mathrm{ZnO}$ crystallites, rather than as a $\mathrm{ZnO}$ supported $\mathrm{Cu}$ catalyst that would usually consist of smaller size Cu-based nanoparticles dispersed on the $\mathrm{ZnO}$ support.

\begin{tabular}{|c|c|c|c|}
\hline Catalyst & $\begin{array}{l}\text { Cu phase } \\
\text { composition }\end{array}$ & $\begin{array}{l}\text { Cu phase mean } \\
\text { crystallite size } \\
(\mathrm{nm})^{*}\end{array}$ & $\begin{array}{l}\text { ZnO mean } \\
\text { crystallite size } \\
(\mathrm{nm})^{*}\end{array}$ \\
\hline CuZnO(I)550 & $\mathrm{Cu}_{0.2 \mathrm{Zn}} \mathrm{n}_{0.8}$ & 32 & 44 \\
\hline CuZnO(I)400 & $\begin{array}{l}\text { Probably inter } \\
\text { metallic } \mathrm{Cu}_{x} Z \mathrm{n}_{\mathrm{y}}\end{array}$ & 20 & 43 \\
\hline CuZnO(I)300 & $\mathrm{Cu}$ & 24 & 46 \\
\hline \multirow[t]{2}{*}{ CuZnO(I)200 } & $\mathrm{Cu}$ & 22 & 45 \\
\hline & $\mathrm{CuO}$ & 13 & \\
\hline $\mathrm{CuZnO}(\mathrm{I})$ & $\mathrm{CuO}$ & 23 & 42 \\
\hline CuZnO(P) & $\mathrm{CuO}$ & 10 & 20 \\
\hline $\mathrm{ZnO}$ & - & - & 10 \\
\hline
\end{tabular}

* defined as the mean size of the coherently-diffracting domains, derived from the Scherrer equation using the classical assumption of spherical crystallites. The full-width at half maximum of the diffraction peaks of $\mathrm{ZnO}(100), \mathrm{Cu}(111)$, $\mathrm{CuO}$ (111) and $\mathrm{Cu}_{0.2 \mathrm{Zn}} \mathrm{Zn}_{0.8}$ (101) planes was used for the estimation.

6 | J. Name., 2012, 00, 1-3
The nature of the $\mathrm{Cu}$ phase progressively turned into metallic $\mathrm{Cu}$ with the increase in the reduction temperature, so that both $\mathrm{Cu}^{(I I)} \mathrm{O}$ and $\mathrm{Cu}^{0}$ phases were observed for the catalyst treated at $200^{\circ} \mathrm{C}$ - with a mean crystallite size of 13 and $22 \mathrm{~nm}$ respectively, while only reflexes corresponding to the diffraction of the (111), (200) and (220) planes of $\mathrm{Cu}^{0}$ (JCPDS 01085-1326) were observed for the $\mathrm{CuZnO}(\mathrm{I}) 300$ catalyst - with no size change.

A further increase in the reduction temperature resulted in the formation of intermetallic CuZn compound, with the presence of additional reflexes in $2 \theta$ at $42.4^{\circ}, 43.5^{\circ}$ and $49.2^{\circ}$ at $550^{\circ} \mathrm{C}$ attributed to the $\mathrm{Cu}_{0.2} \mathrm{Zn}_{0.8}$ alloy phase, ${ }^{31}$ with a mean crystallite size of $32 \mathrm{~nm}$. At the intermediate temperature of $400^{\circ} \mathrm{C}$, the observed reflexes might be attributed to an intermetallic CuZn phase with a different composition. By contrast, the mean $\mathrm{ZnO}$ crystallite size was not affected by the reduction step under hydrogen and remained within the $42-46 \mathrm{~nm}$ range. 


\section{Characterization of used and post-reaction treated catalysts.}

Figure 2 and Table 5 show the influence of the 1st catalyst cycling on the XRD patterns of both CuZnO catalysts and on the derived mean crystallite sizes. Besides the reflexes of the $\mathrm{ZnO}$ support, the pattern of the used $\mathrm{CuZnO}(\mathrm{I})$ evidenced the reflexes of the metallic $\mathrm{Cu}$ phase, with a mean crystallite size of $28 \mathrm{~nm}$, characterizing the bulk reduction of $\mathrm{CuO}$ into metallic $\mathrm{Cu}$ during the catalytic reaction under pressured hydrogen. The further recalcination of the used $\mathrm{CuZnO}(\mathrm{I})$ resulted in the reoxidation of the metallic copper into both $\mathrm{CuO}$ and $\mathrm{Cu}_{2} \mathrm{O}$ phase, with a smaller mean crystallite size of $11 \mathrm{~nm}$ and $12 \mathrm{~nm}$, respectively. When it comes to the $\mathrm{CuZnO}(\mathrm{P})$ catalyst, the reaction induced a reduction of the pristine monoclinic $\mathrm{CuO}$ crystallites into cubic $\mathrm{Cu}_{2} \mathrm{O}$ crystallites (JCPDS Card 00-0050667) with a mean crystallite size of $41 \mathrm{~nm}$, whereas a broad peak corresponding to metallic $\mathrm{Cu}$ was observed. After the calcination treatment of the used $\mathrm{CuZnO}(\mathrm{P})$ catalyst, the both $\mathrm{Cu}_{2} \mathrm{O}$ and $\mathrm{CuO}$ crystallites were observed, with a mean crystallite size of $15 \mathrm{~nm}$ and $12 \mathrm{~nm}$. The mean crystallite size of the $\mathrm{ZnO}$ support was not affected by the treatments applied, considering the accuracy of the measurements.

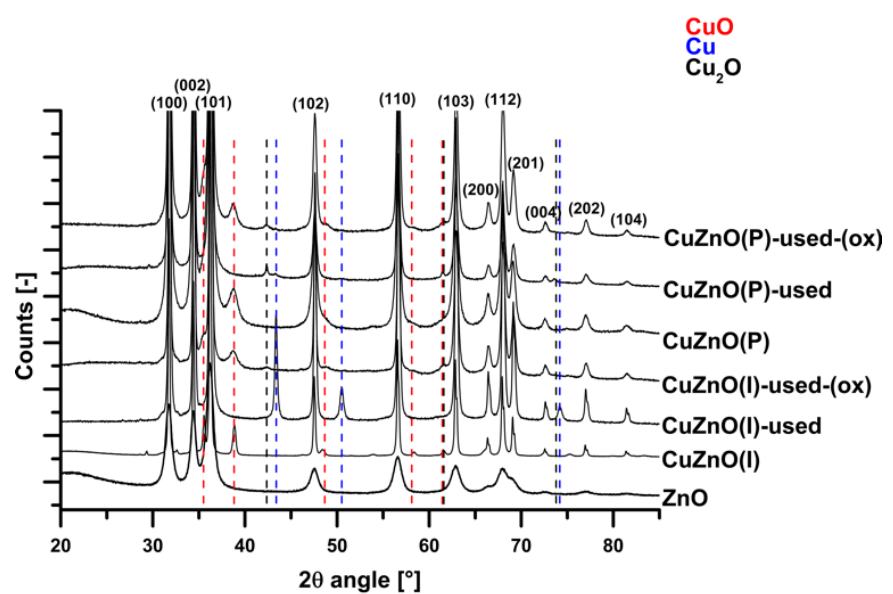

Figure 2. X-Ray Diffraction patterns of the bare $\mathrm{ZnO}$ support and both $\mathrm{CuZnO}(\mathrm{P})$ and $\mathrm{CuZnO}(\mathrm{I})$ catalysts, fresh, after test and after test followed by intermediate calcination at $300^{\circ} \mathrm{C}$. The crystallographic planes indicated correspond to the diffraction planes of the $\mathrm{ZnO}$ support

In addition, Rietvelt refinement of diffractograms showed that no incorporation of copper ions within the zinc oxide support lattice occurred, neither during the catalyst preparation step, nor during the reaction at $220^{\circ} \mathrm{C}$ under 30 bar of hydrogen or the intermediate re-oxidation step after test, regardless of the synthesis method used (Table S1).

The $\mathrm{CuZnO}(\mathrm{I})$ catalyst shows higher temperature stability and the particle size stays nearly stable during the reaction. The reoxidation step allows to reach smaller particle size that is then kept during the further oxidation cycles (Table S2). By contrast, the $\mathrm{CuZnO}(\mathrm{P})$ catalyst is more prone to changes as the initial photoassisted synthesis treatment was performed at room temperature. In the presence of reductive reaction conditions, larger $\mathrm{Cu}_{2} \mathrm{O}$ nanoparticles are formed, which redispersed to the initial size during their reoxidation step forming back $\mathrm{CuO}$.
Figure 3 and 4 shows SEM and TEM images, respectively, of selected $\mathrm{CuZnO}(\mathrm{I})$ and $\mathrm{CuZnO}(\mathrm{P})$ catalysts during the test cycling procedure. The SEM images indicate that the overall morphology of the ZnO-based materials was not modified by the $\mathrm{Cu}$ nanoparticle synthesis processes compared to the bare support (Figure S1), except a more marked increase in the mean $\mathrm{ZnO}$ particle size in the case of the CuZnO(I) samples compared to the $\mathrm{CuZnO}(\mathrm{P})$ counterpart. The electronic similarity between $\mathrm{Cu}$ and $\mathrm{Zn}$ did not enable to discriminate between both oxide particles and mainly surface topographic contrast was observed. However, overall EDS analysis evidenced the presence of copper within the catalysts. Only imaging in the back-scattered mode enabled to visualize the distribution of the metallic $\mathrm{Cu}$ nanoparticles in the catalysts after test, as shown in the case of the used CuZnO(P).

Table 5. Main physicochemical properties derived from XRD patterns of both $\mathrm{CuZnO}(\mathrm{I})$ and $\mathrm{CuZnO}(\mathrm{P})$ catalysts, fresh, after test and after test followed by intermediate calcination at $300^{\circ} \mathrm{C}$.

\begin{tabular}{|c|c|c|c|}
\hline Catalyst & $\begin{array}{l}\text { Cu phase } \\
\text { composition }\end{array}$ & $\begin{array}{l}\text { Cu phase } \\
\text { mean } \\
\text { crystallite size } \\
(\mathrm{nm})^{*}\end{array}$ & $\begin{array}{l}\text { ZnO mean } \\
\text { crystallite size } \\
(\mathrm{nm})^{*}\end{array}$ \\
\hline CuZnO(I) & $\mathrm{CuO}$ & 23 & 42 \\
\hline $\begin{array}{l}\text { CuZnO(I)- } \\
\text { used }\end{array}$ & $\mathrm{Cu}$ & 28 & 36 \\
\hline CuZnO(I)- & CuO & 11 & \multirow{2}{*}{39} \\
\hline used-(ox) & $\mathrm{Cu}_{2} \mathrm{O}$ & 12 & \\
\hline CuZnO(P) & $\mathrm{CuO}$ & 10 & 20 \\
\hline $\begin{array}{l}\text { CuZnO(P)- } \\
\text { used }\end{array}$ & $\begin{array}{l}\mathrm{Cu} \\
\mathrm{Cu}_{2} \mathrm{O}\end{array}$ & $\begin{array}{l}\text { n.d. } \\
41\end{array}$ & 23 \\
\hline $\begin{array}{l}\text { CuZnO(P)- } \\
\text { used-(ox) }\end{array}$ & $\begin{array}{l}\mathrm{CuO} \\
\mathrm{Cu}_{2} \mathrm{O}\end{array}$ & $\begin{array}{l}12 \\
15\end{array}$ & 20 \\
\hline
\end{tabular}

*defined as the mean size of the coherently-diffracting domains, derived from the Scherrer equation using the classical assumption of spherical crystallites. The fullwidth at half maximum of the diffraction peaks of $\mathrm{ZnO}(100), \mathrm{Cu}(111), \mathrm{Cu}_{2} \mathrm{O}(200)$ and $\mathrm{CuO}$ (111) was used for the estimation.

Figure 4a,b evidences the general morphology of the $\mathrm{ZnO}$ support material prepared through the carbonate precipitation method, with interplanar spacings of $0.28 \mathrm{~nm}$ and $0.25 \mathrm{~nm}$ consistent with the (100) and (101) planes of hexagonal wurtzite ZnO crystallites, ${ }^{32}$ and with crystallite sizes in agreement with those derived from the XRD patterns. When it comes to the CuZnO catalysts, whatever the applied treatments, the similarities of the interplanar spacings corresponding to the main planes of $\mathrm{ZnO}$ and of both $\mathrm{CuO}$ or $\mathrm{Cu}_{2} \mathrm{O}$ crystallites did not allow the specific identification and location of the phases in the different CuZnO catalysts that consisted of oxide crystallites in very close contact. However, overall EDS analysis and mapping STEM images confirmed the presence of copper in both samples (Figure S2). The TEM images of both fresh catalysts confirmed as well that the growth of $\mathrm{ZnO}$ crystallites was more 
pronounced during the preparation by the impregnation method that during the photoassisted one.

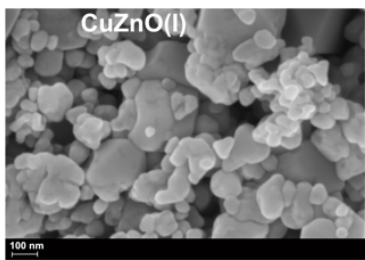

a)
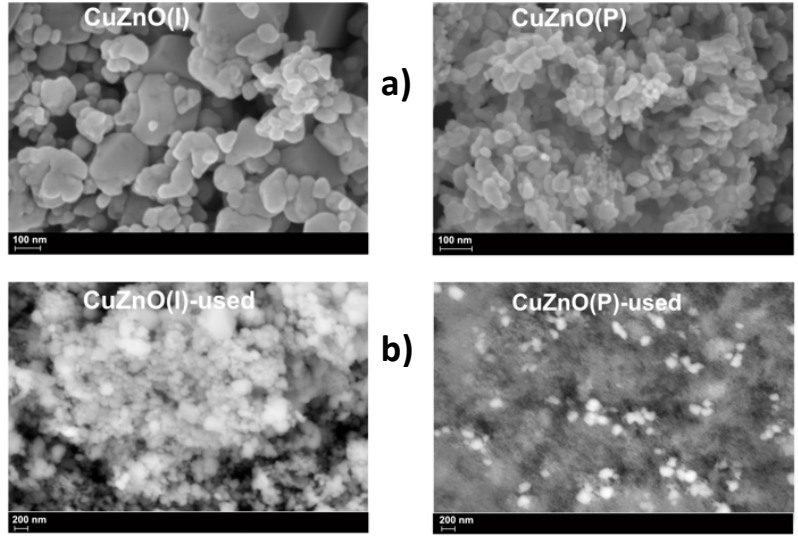

b)
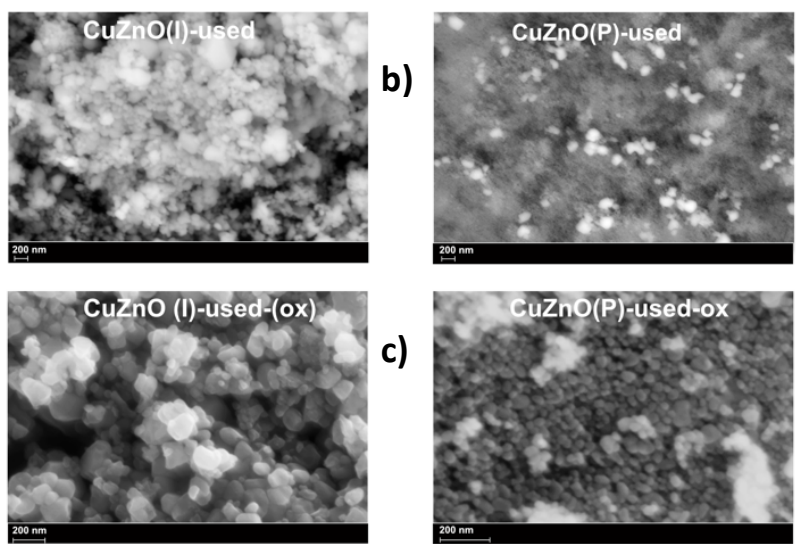

c)

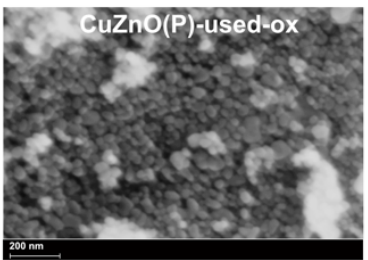

Figure 3. SEM images of both $\mathrm{CuZnO}(\mathrm{I})$ and $\mathrm{CuZnO}(\mathrm{P})$ catalysts as a function of the test cycle : fresh, used and used/reoxidized. The right (b) image was taken in the backscattered mode for evidencing in a more pronounced way the contrast between metallic $\mathrm{Cu}$ and $\mathrm{ZnO}$.

By contrast, the images recorded on the used catalysts reveal the presence of metallic Cu nanoparticles in very close contact with the $\mathrm{ZnO}$ crystallites, as evidenced in Figure $4 \mathrm{f}$ for instance in the case of the catalyst prepared via the impregnation method, with the interplanar spacing of $0.21 \mathrm{~nm}$ consistent with the (111) planes of metallic copper (JCPDS No. 01-085-1326).

When it comes to the used catalysts after the reoxidation step, the difficulty to visualize the $\mathrm{Cu}$ based phase within the CuZnO samples confirmed the bulk reoxidation of the metallic Cu nanoparticles observed by XRD (not shown).

The influence of the catalyst preparation method and of the treatment applied (fresh, used and used catalyst after reoxidation step) on the surface state of the CuZnO catalysts is shown in Figure 5 and S3. The Zn $2 p$ orbital XPS spectra exhibit a single contribution, with the doublet related to $\mathrm{Zn} 2 \mathrm{p}_{3 / 2}$ and $2 \mathrm{p}_{1 / 2}$ spin-orbit components of $\mathrm{Zn}^{2+}(\mathrm{Zn}-\mathrm{O})$ surface species, at 1021.1 and $1044.2 \mathrm{eV}$, in agreement with the literature. ${ }^{35}$ While the same surface species were observed on the CuZnO(I) catalyst, it was worth noting the presence of an additional doublet contribution at 1022.8 and $1045.9 \mathrm{eV}$ for the CuZnO(P) catalyst. This higher energy contribution was attributed to $\mathrm{Zn}^{2+}$ in a different chemical environment, and was assigned to $\mathrm{Zn}-\mathrm{O}-$ $\mathrm{Cu}$ bonds. Indeed, in an electrostatic model, the higher electronegativity of $\mathrm{Cu}$ compared to $\mathrm{Zn}$ resulted in a $\mathrm{O} \rightarrow \mathrm{Cu}$ electron transfer in a $\mathrm{Zn}-\mathrm{O}-\mathrm{Cu}$ configuration, that would consequently lead to shift the electronic density of the $\mathrm{Zn}-\mathrm{O}$ bond towards the oxygen atoms, therefore increasing the electron deficiency of the $\mathrm{Zn}$ atoms. This partial substitution of $\mathrm{Zn}^{2+}$ by $\mathrm{Cu}^{2+}$ might occur only at the surface of the CuZnO catalyst prepared through the photoassisted synthesis, since $\mathrm{ZnO}$ is prone to surface photocorrosion under irradiation. $32,36,37$
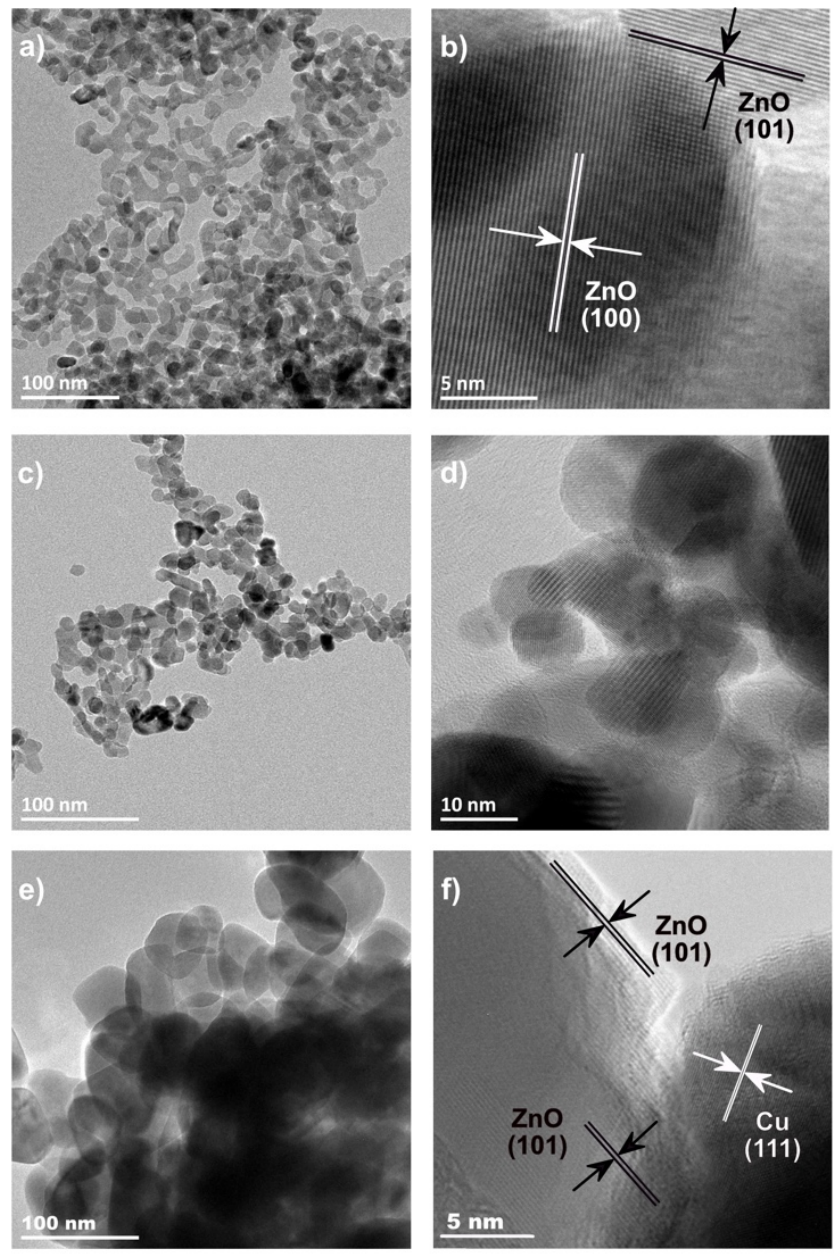

Figure 4. TEM images of $(a, b)$ the $\mathrm{ZnO}$ support, $(c, d)$ the fresh CuZnO(P) catalyst, (e) the fresh CuZnO(I) catalyst, and (f) the used CuZnO(I) catalyst. The (101) and (100) planes of $\mathrm{ZnO}$ have interplanar distances of $0.25 \mathrm{~nm}$ and $0.28 \mathrm{~nm}$ (JCPDS No.00-036-1451), while the (111) and (002) planes of the $\mathrm{CuO}$ phase have $0.23 \mathrm{~nm}$ and $0.25 \mathrm{~nm}$ interplanar distances (JCPDS No. 01-089-5895), and the (111) planes of the $\mathrm{Cu}_{2} \mathrm{O}$ phase have 0.25 $\mathrm{nm}$ interplanar distances, respectively (JCPDS No. 00-005-0667) ${ }^{33,34}$

In the case of the CuZnO(I) catalyst, no difference was observed in terms of Zn surface species neither directly after the reaction on the used catalyst, nor after the reoxidation of the used catalyst. By contrast, the spectra recorded on the used CuZnO(P) catalyst revealed the appearance of a new doublet contribution at 1019.8 and $1042.9 \mathrm{eV}$. This lower energy contribution was attributed to $\mathrm{Zn}^{\delta+}$ species $\left(\mathrm{ZnO}_{\mathrm{x}}\right)$ that may be formed at the interface with copper under the highly reductive reaction conditions. The presence of partially oxidized $\mathrm{Zn}^{\delta+}$ species was observed by Behrens et al. at the defective $\mathrm{Cu}$ surface of a high-performance $\mathrm{Cu} / \mathrm{ZnO} / \mathrm{Al}_{2} \mathrm{O}_{3}$ catalyst for methanol synthesis as a result of a dynamic SMSI effect with reduction of $\mathrm{ZnO}$ particles leading to partial coverage of the metal particles with $\mathrm{ZnO}_{x}{ }^{38}$ This additional partially oxidized contribution was removed during the subsequent reoxidation step of the used CuZnO(P) catalyst. 


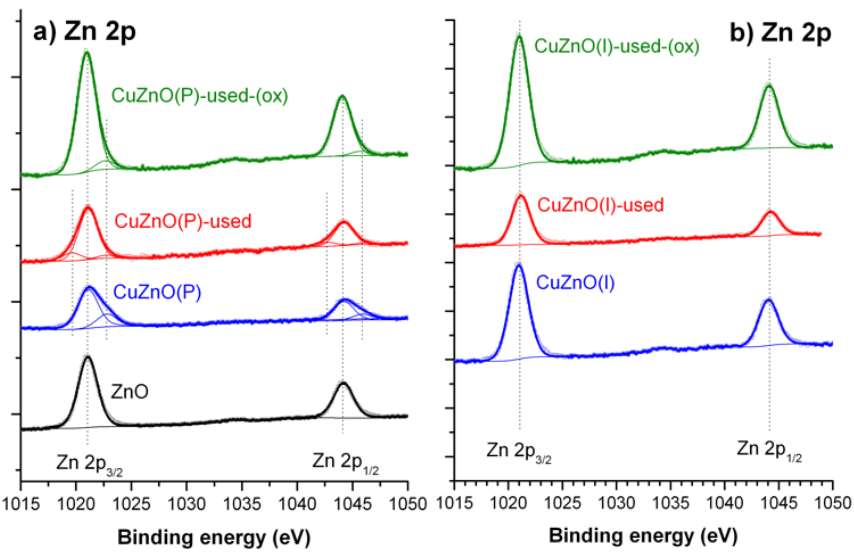

Figure 5. Influence of the CuZnO catalyst preparation method and of the treatment applied (fresh, used and used catalyst after reoxidation step) on the $\mathrm{Zn} 2 \mathrm{p} 3 / 2$ and $2 \mathrm{p} 1 / 2$ orbital region. (a) photoassisted method ; (b) impregnation method.

Whatever the preparation method, the $\mathrm{Cu} 2 \mathrm{p}$ orbital XPS spectra shows the presence $\mathrm{Cu}^{2+}$ species at the surface of the fresh catalysts, with a broad doublet contribution (main orbital peak at $932.5 \mathrm{eV}$ ) and the usual broad and badly-resolved satellite features of $\mathrm{Cu}^{2+}$ species (Figure S3). The thinner doublet contribution observed on the used catalysts was in agreement with the formation of metallic copper observed by XRD analysis, although XPS does not allow to discriminate between metallic copper and $\mathrm{Cu}^{+}$species. Further, the peak asymmetry indicated that surface oxidation of the copper species occurred. The surface of the used reduced catalysts turned back to $\mathrm{Cu}^{2+}$ during the reoxidation step of both used catalysts, with the observation of broader and slightly shifted peaks.

\section{The reducibility of the catalysts}

The reducibility of the CuZnO catalysts (fresh and after reoxidation treatment) was investigated by TPR measurements. The TPR profile of the fresh $\mathrm{CuZnO}(\mathrm{I})$ catalyst presented in Figure $6 \mathrm{~A}$ shows a broad reduction peak with several contributions within the $180-400^{\circ} \mathrm{C}$ temperature region and a very small effect at $400-650^{\circ} \mathrm{C}$. This complex TPR profile results, first from the two-step reduction of the Cull species in $\mathrm{CuO}$ to $\mathrm{Cu}^{\mathrm{l}}$ and subsequently to $\mathrm{Cu}^{0} 39$ and from the presence of different types of species differing in terms of size, dispersion, and interaction with the support. The low temperature small peak $\left(180-220^{\circ} \mathrm{C}\right)$ results probably from amorphous, small size, weekly interacting with the support Cu species. ${ }^{40,41}$
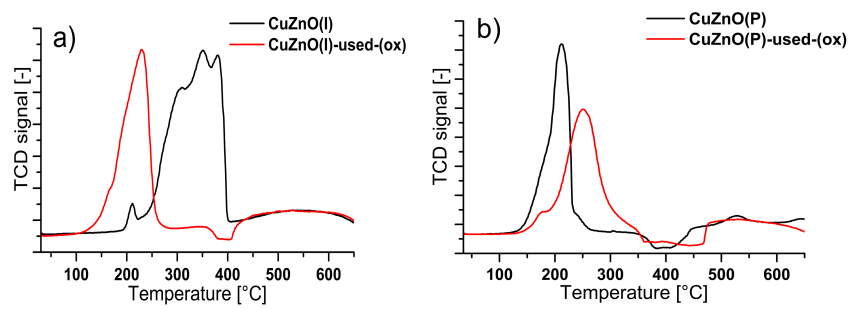

Figure 6. TPR profiles of a) the $\mathrm{CuZnO}(\mathrm{I})$ and $\mathrm{b})$ the $\mathrm{CuZnO}(\mathrm{P})$ catalysts, fresh and after reoxidation treatment.
The main effect $\left(180-400^{\circ} \mathrm{C}\right)$ is related with the step-wise reduction of $\mathrm{CuO}$ that is also directly affected by the presence of crystalline $\mathrm{CuO}_{x}$ nanoparticles of different sizes, additionally interacting with the support differently - the stronger the interaction, the higher the reduction temperature. ${ }^{39,42,43}$

Final reduction effect at high temperatures in the range of $400-700^{\circ} \mathrm{C}$ can be connected with the reduction of $\mathrm{Cu}^{2+}$ species which are in strong interaction with the support, with further CuZn alloy formation. ${ }^{44}$

After recalcination of the used catalyst, the TPR profile is shifted to lower temperature in comparison to the fresh $\mathrm{CuZnO}(\mathrm{I})$, and only one reduction peak is visible, with a maximum at $230^{\circ} \mathrm{C}$. It may be related to a redistribution of smaller CuO crystallites. ${ }^{45}$ It shows clearly that the $\mathrm{Cu}$ species are more susceptible to be reduced.

The TPR profiles of the CuZnO(P) catalysts prepared through the photon-assisted method are presented in Figure 6B. TPR profile of the fresh $\mathrm{CuZnO}(\mathrm{P})$ shows two reduction effects, in the $125-290^{\circ} \mathrm{C}$ and $400-760^{\circ} \mathrm{C}$ temperature range. The first asymmetric peak with a maximum at $210^{\circ} \mathrm{C}$ strongly shifted to low temperature when compared to the fresh $\mathrm{CuZnO}(\mathrm{I})$ catalyst, may be assigned to the two-step reduction of $\mathrm{CuO}$, but in this case with much smaller and more uniform crystallite size. The second effect at high temperature, as in the case of the CuZnO(I) catalysts, may be related with the reduction of $\mathrm{Cu}^{2+}$ in strong interaction with the support.

After oxidation of the used CuZnO(P) catalyst, a slight change of the position of the reduction peak in comparison to fresh catalyst is visible which can occur due to the thermal reduction treatment. However, the changes of the reduction temperature are not so much pronounced like for the $\mathrm{CuZnO}(\mathrm{I})$ counterpart and the reduction temperature maximum for the catalyst after the reoxidation step remains in the same range as for the $\mathrm{CuZnO}(\mathrm{I})$ counterpart after the similar cycling treatment.

\section{FTIR analysis of the acetone adsorption on the catalyst surface}

The first step of the HMF hydrodeoxygenation reaction requires carbonyl group adsorption. Therefore, acetone was chosen as a probe molecule and its adsorption was monitored by FTIR study (Figure 7). The main, broad band at $1710 \mathrm{~cm}^{-1}$ can be assigned to the carbonyl group vibrations of acetone ${ }^{46}$ and the small band located in the range of $1680-1670 \mathrm{~cm}^{-1}$ can be assigned to mesityl oxide carbonyl group vibrations. ${ }^{47}$ Acetone adsorption allows to investigate formation of the acid centres of the catalyst due to the formation of the mesityl oxide. Mesityl oxide originates from aldol condensation of two adsorbed acetone molecules via dehydration reaction which occurs on acid centers. ${ }^{48,49}$

The highest acetone adsorption is visible for the CuZnO(I) catalyst, however after reaction no characteristic band at 1710 $\mathrm{cm}^{-1}$ is observed any more. It can be related with the formation of $\mathrm{Cu}^{0}$. Additionally it cannot be fully excluded that active sites are partially blocked by carbon deposit formed during the test.

After recalcination of $\mathrm{CuZnO}(\mathrm{I})$ much smaller band is observed, additionally a small, broad band at $1680 \mathrm{~cm}^{-1}$ appears, which can be assigned to the carbonyl group vibrations 
of the mesityl oxide. Therefore it can be assumed that during the postreaction treatment of the $\mathrm{CuZnO}(\mathrm{I})$ catalyst, formation of the acidic centres occurs. In case of the $\mathrm{CuZnO}(\mathrm{P})$ catalyst prepared with photon-assisted deposition method, the acetone adsorption is significantly smaller than in case of $\mathrm{CuZnO}(\mathrm{I})$. This might be related with stronger CuO-ZnO interaction and therefore and presence of the $\mathrm{Cu}-\mathrm{O}-\mathrm{Zn}$ bonds due to the partial dissolution of $\mathrm{Cu}^{2+}$ ions in the $\mathrm{ZnO}$ lattice, which may influence of the acetone adsorption.

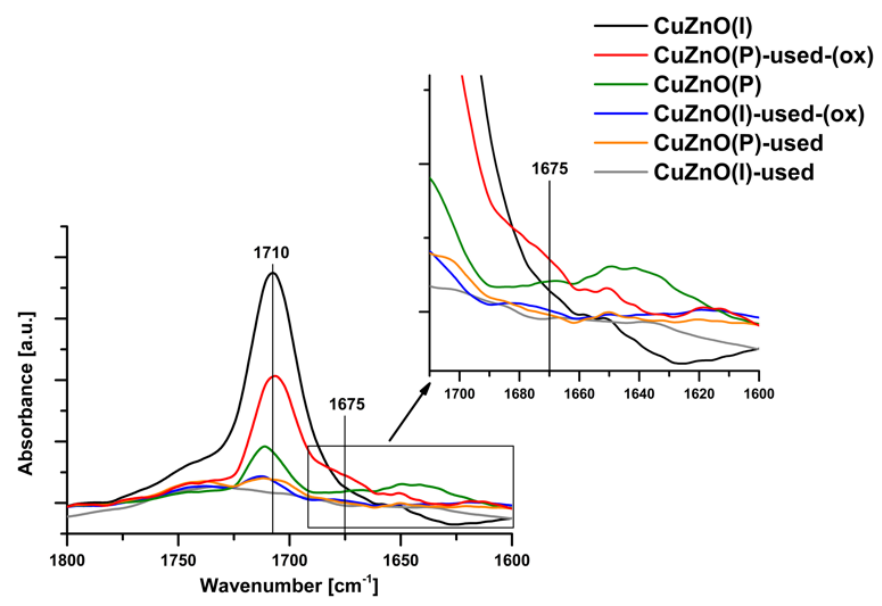

Figure 7. Acetone-adsorbed FTIR profiles for $\mathrm{CuZnO}(\mathrm{I})$ and $\mathrm{CuZnO}(\mathrm{P})$ catalysts according to the recycling treatment

What is more, interaction of copper oxide with $\mathrm{ZnO}$, increases the electron density of $\mathrm{Cu}$ by charge transfer from $\mathrm{ZnO}$ with formation of copper species with lower positive charge $\mathrm{Cu}^{(2-\delta)+}$. This effect is enhanced for low $\mathrm{Cu}$ content catalyst and for the small $\mathrm{CuO}$ particle size as in the case of $\mathrm{CuZnO}(\mathrm{P}) .^{50}$

Interestingly, for the CuZnO(P) the band of mesityl oxide $\mathrm{C}=\mathrm{O}$ is present also for the fresh catalyst. This can be related with the presence of $\mathrm{Zn}-\mathrm{O}-\mathrm{Cu}$ sites at the surface of the catalyst, as putted forward by the XPS study, which can serve as Lewis acid center, allowing dehydration of the adsorbed molecule. Although after reaction the decrease of the intensity of the acetone $\mathrm{C}=\mathrm{O}$ group vibration band is observed, in contrast to the $\mathrm{CuZnO}(\mathrm{I})$, acetone adsorption still occurs, what may be also related with the presence of $\mathrm{Zn}-\mathrm{O}-\mathrm{Cu}$ sites (although in a lower extent) and/or with the formation during the reaction of partially oxidized $\mathrm{Zn}^{\delta+}$ centers or of $\mathrm{Cu}_{2} \mathrm{O}$ species. Further calcination of the used catalyst causes an increase in the amount of adsorbed acetone. What is more, increase of formation of mesityl oxide was also noted, what suggests, that further formation of the acid sites occurred.

\section{Catalyst stability characterization}

In order to investigate the stability of investigated catalyst FAAS measurements of the reaction liquid and ToF-SIMS measurements of the catalyst surface were performed. FAAS measurements revealed that in case of the catalyst prepared via wet impregnation method no leaching of the $\mathrm{Cu}^{2+}$ or $\mathrm{Zn}^{2+}$ occurs, whereas in case of the catalyst prepared via photonassisted deposition method only slight leaching of both copper and zinc ions take place, with ions release smaller than $0.3 \%$ wt of the initial amount in the catalyst. Therefore, leaching cannot be considered as a reason for catalyst deactivation during recycling tests. ToF-SIMS analysis of the catalyst surface was performed to further investigate the deactivation phenomena of the catalysts (Table 6).

Table 6. The intensity ratios of selected ions calculated on the basis of the ToF-SIMS mass spectra collected from the surface of $\mathrm{CuZnO}(\mathrm{P})$ and $\mathrm{CuZnO}(\mathrm{I})$ catalysts after tests

\begin{tabular}{lll}
\hline Catalysts $^{\mathrm{a}}$ & $\mathrm{C}^{+} / \mathrm{Cu}^{+}$ & $\mathrm{C}^{+} / \mathrm{Zn}^{+}$ \\
\hline $\mathrm{CuZnO}(\mathrm{I})$ (fresh) & 0.103 & 0.094 \\
$\mathrm{CuZnO}(\mathrm{I})$ after $1^{\text {st }}$ test & 0.062 & 0.119 \\
$\mathrm{CuZnO}(\mathrm{I})$ after $3^{\text {rd }}$ test & 0.504 & 1.540 \\
$\mathrm{CuZnO}(\mathrm{P})$ (fresh) & 0.086 & 0.161 \\
$\mathrm{CuZnO}(\mathrm{P})$ after $1^{\text {st }}$ test & 0.245 & 0.820 \\
$\mathrm{CuZnO}(\mathrm{P})$ after $3^{\text {rd }}$ test & 1.430 & 3.120 \\
\hline
\end{tabular}

a the catalysts were submitted to an intermediate oxidation step at $300^{\circ} \mathrm{C}$ between each test during the cycling procedure.

In the case of the $\mathrm{CuZnO}(\mathrm{I})$ catalysts, both $\mathrm{C}^{+} / \mathrm{Cu}^{+}$and $\mathrm{C}^{+} / \mathrm{Zn}^{+}$ ratios are gradually increasing from around 0.1 for the fresh catalyst (that corresponds to the usual background ratio) up to 0.5 for $\mathrm{C}^{+} / \mathrm{Cu}^{+}$and 1.5 for $\mathrm{C}^{+} / \mathrm{Zn}^{+}$for the catalyst after the $3^{\text {rd }}$ test cycle. Similar observations can be made for the $\mathrm{CuZnO}(\mathrm{P})$ catalyst, where both $\mathrm{C}^{+} / \mathrm{Cu}^{+}$and $\mathrm{C}^{+} / \mathrm{Zn}^{+}$ratios are increasing from 0.086 and 0.161 values up to 1.430 and 3.120, respectively. Therefore, the results indicated that carbon deposition may be a reason for the catalyst deactivation which occurs during the recycling tests.

\section{Discussion}

We believe that the presence of $\mathrm{Cu}^{\text {n+ }}$ is necessary in the initial reaction step for facilitating the pre-adsorption of HMF on the surface via the $\mathrm{C}=\mathrm{O}$ bond, since it has been reported that both $\mathrm{Cu}^{2+}$ and $\mathrm{Cu}^{+}$centers

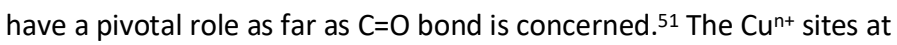
the catalyst surface can act as electrophilic or Lewis acidic centers for polarizing the $\mathrm{C}=\mathrm{O}$ bond via the lone electron pair in oxygen, with as consequence an enhancement of the $\mathrm{C}=\mathrm{O}$ adsorption and of the activity. ${ }^{52}$

This enhancement was noticed in several processes which require a $\mathrm{C}=\mathrm{O}$ bond hydrogenation, such as the hydrogenation of dimethyloxalate to ethanol 53 or the hydrogenation of adipic acid to 1,6-hexanediol. ${ }^{54}$ Although direct relationship between the number of $\mathrm{Cu}^{+}$or $\mathrm{Cu}^{2+}$ centers and the activity is only scarcely observed, ${ }^{54}$ the role of $\mathrm{Cu}^{\mathrm{nt}}$ ions is often related to the stabilization of reaction intermediates, like the methoxy and acyl species in the methyl acetate hydrogenation ${ }^{53}$ or in LA hydrogenation. ${ }^{55}$

In our case, the surface of $\mathrm{CuZnO}(\mathrm{I})$ exposing $\mathrm{Cu}^{2+}$ sites was characterized by a high adsorption, whereas the high HMF conversion is reached already after $0.5 \mathrm{~h}$ of reaction. The same catalyst is fully reduced after the reaction cycle and thus did not exhibit any 
adsorption, and consequently no HMF conversion in the reaction is obtained when the catalyst is reused as-it with no intermediate treatment. This contrasts with the $\mathrm{CuZnO}(\mathrm{P})$ catalyst, which is not fully fro reduced after reaction - with the presence of the $\mathrm{Cu}_{2} \mathrm{O}$ phase in dur addition to the metallic copper - and therefore allows HMF adsorption via the $\mathrm{C}=\mathrm{O}$ bond to occur. As a result, $\mathrm{HMF}$ conversion can further proceed on the used catalyst during the next test cycle without any intermediate treatment.

Although the $\mathrm{Cu}^{\mathrm{n}+}$ sites are required for the first step, namely the HMF adsorption on the catalysts via the $\mathrm{C}=\mathrm{O}$ bond, they are however not the active sites for the hydrogenation process. Indeed $\mathrm{Cu}^{0}$ is formed in situ in the process, and its role is related to the dissociation of $\mathrm{H}_{2}$ and to the reduction of the $\mathrm{C}=\mathrm{O}$ bond, so that a cooperative effect associated to the presence of metallic and $\mathrm{Cu}^{\text {n+ }}$ sites is necessary. This is in agreement with the literature reports concerning other hydrogenation processes. ${ }^{56}$

The HMF adsorption via the $\mathrm{C}=\mathrm{O}$ bond and the subsequent efficient reduction of the $\mathrm{C}=\mathrm{O}$ bond enable to get high yield to $\mathrm{BHMF}$, while the further reduction towards DMF implies $\mathrm{C}-\mathrm{O}$ hydrogenolysis to take place, for which the presence of both $\mathrm{Cu}^{0}$ and acid sites is required.

Oxygen vacancies in $\mathrm{ZnO}$ that act as Lewis acid sites can be formed at the $\mathrm{ZnO}-\mathrm{CuO}$ interfacial sites, due to the existence of stronger interactions between $\mathrm{ZnO}$ and $\mathrm{Cu}$ species. ${ }^{57}$ The increased synergy within $\mathrm{ZnO}_{x}-\mathrm{CuO}_{\mathrm{x}}$ phases was already proposed as an important factor promoting the activity, particularly in the case of methanol synthesis. Valant et al. showed recently that the activity of the $\mathrm{Cu}-\mathrm{ZnO}$ catalyst in the methanol synthesis is directly correlated to the number of contact points between $\mathrm{Cu}$ species and $\mathrm{ZnO}$ nanoparticles. ${ }^{58}$ From the other hand, Behrens et al. proposed that the $\mathrm{Cu}-\mathrm{ZnO}$ synergy was related to the presence of $\mathrm{Zn}^{\delta+}$ at the Cu surface (steps/defects), which might result from a strong $\mathrm{Cu}-\mathrm{ZnO}$ interaction allowing a partial coverage of the $\mathrm{Cu}$ surface with $\mathrm{ZnO}_{x}$ under reducing conditions. This could result in the increase in the binding strength of intermediates and in the decrease of reaction barriers in $\mathrm{CO}$ hydrogenation. ${ }^{38}$

This may explain why the reaction goes forward towards further hydrogenation products like DMF in the case of the $\mathrm{CuZnO}(\mathrm{P})$ catalyst, whereas by contrast the reaction is stopped on the $\mathrm{CuZnO}(\mathrm{I})$ catalyst despite the latter shows a slightly higher activity. Lewis acid sites were formed on $\mathrm{CuZnO}(\mathrm{P})$ during the photo-assisted synthesis procedure as $\mathrm{ZnO}$ is prone to surface photocorrosion under irradiation. Their presence was confirmed by the formation of mesityl oxide during the IR study with acetone as probe molecule. Their formation was noticed also for the used $\mathrm{CuZnO}(\mathrm{I})$ catalyst after reoxidation treatment and this directly resulted in pushing the selectivity of the reaction. Additionally the most active catalyst - CuZnO(P) - that allows to reach high DMF yield had small size Cu particles $(\sim 10 \mathrm{~nm})$, that probably facilitates the phase contact within the $\mathrm{CuO}_{\mathrm{x}}-\mathrm{ZnO}$ material.

Finally we showed that the catalysts can be further activated during the reaction, and thanks to that, that the reaction selectivity can be tuned. The possibility of tuning the reaction selectivity was shown already in this reaction, however only by changing the reaction conditions, like by elevating the temperature or the pressure. Indeed, mild reaction conditions allowed the formation of BHMF, whereas DMF was the main product in harsh conditions. ${ }^{19}$ This was however followed by a fast deactivation of the catalyst already in the second reaction cycle.
In our case, the high activity obtained was proposed to result from the formation of Lewis acid sites (Cu-ZnO interfacial sites), as well as from the migration and the redispersion of $\mathrm{Cu}$ particles that can occur during both the reduction and the reoxidation treatments. ${ }^{59,60}$

\section{Conclusions}

In this work, we showed that robust $10 \% \mathrm{CuZnO}$ catalysts allow both BHMF or DMF products to be obtained with high yields from HMF. The selectivity was proposed to depend on the presence of acid sites at the catalyst surface, that might probably correspond to $\mathrm{ZnO}_{x}-\mathrm{CuO}$ and/or Zn-O-Cu interfacial sites. Those sites can be formed during the photo-assisted synthesis of the CuZnO catalyst, or can be created in situ in the highly reductive reaction environment. The catalyst prepared at room temperature through the photoassisted method possesses acid sites, what enable the direct DMF formation. By contrast, those acid sites were only generated during the reaction on the catalyst prepared via the classical wet impregnation method. What is more, we have concluded that high HMF conversion is possible when $\mathrm{Cu}^{\text {n+ }}$ and $\mathrm{Cu}{ }^{\circ}$ sites are present, as $\mathrm{Cu}^{\text {n+ }}$ allows for HMF adsorption via the $\mathrm{C}=\mathrm{O}$ bond, while $\mathrm{Cu}^{\circ}$ allows for $\mathrm{H}_{2}$ dissociation and reduction.

Before subsequent reaction cycles, re-oxidation of the CuZnO catalyst needs to be performed, what can lead to the redispersion of $\mathrm{Cu}$ particles. This oxidative treatment allows to obtain active and selective catalyst for several reaction cycles. By contrast, performing the reduction of the $\mathrm{CuZnO}$ catalyst at high temperature $\left(300-550^{\circ} \mathrm{C}\right)$ before the reaction, can result in the CuZn alloy formation and only marginal HMF conversion can be obtained.

\section{Conflicts of interest}

There are no conflicts to declare.

\section{Acknowledgements}

The authors gratefully acknowledge that this work was financially supported by a grant from the National Center of Science (NCN) in Krakow (Poland) (2016/22/E/ST4/00550). This research was co-funded by the EU Erasmus+ program. T. Dintzer and V. Papaefthimiou (ICPEES) are thanked for performing SEM and XPS analysis, respectively. C. Lefèvre (IPCMS Strasbourg) and W. Maniukiewicz (LUT) are thanked for contributing to XRD.

\section{Notes and references}

1 S. Shafiee and E. Topal, Energy Policy, 2009, 37, 181.

2 R. A. Sheldon, Green Chemistry, 2014, 16, 950.

3 A. M. Ruppert, K. Weinberg and R. Palkovits, Angewandte Chemie International Edition, 2012, 51, 2564.

4 J.J. Bozell and G.R. Petersen, Green Chemistry, 2010, 12, 539.

5 Y. Jiang, A. J. J. Woortman, G. O. R. A. van Ekenstein, D. M. Petrović and K. Loos, Biomacromolecules, 2014, 2482. 
6 L. Hu, J. Xu, S. Zhou, A. He, X. Tang, L. Lin, J. Xu and Y. Zhao, ACS Catalysis, 2018, 8, 2959.

7 R. Daniel, G. Tian, H. Xu i S. Shuai, Fuel, 2012, 99, 72.

8 G. Tian, R. Daniel, H. Li, H. Xy, S. Shuai and P. Richards, Energy Fuels, 2010, 24, 3898.

9 S. Chen, R. Wojcieszak, F. Dumeignil, E. Marceau and S. Royer, Chemical Reviews, 2018, 118, 11023.

10 M. Besson, P. Gallezot and C. Pinel, Chemical Reviews, 2014, 114, 1827.

11 X. Wang, X. Liang, J. Li i Q. Li, Applied Catalysis A: General, 2019, 576, 85.

12 J. Luo, M. Monai, C. Wang, J. D. Lee, T. Duchon, F. Dvorak, V. Matolin, C. B. Murray, P. Fornasiero and R. J. Gorte, Catalysis Science and Technology, 2017, 17, 1735.

13 J. M. Requies, M. Frias, M. Cuezva, A. Iriondo, I. Agirre i N. Viar, Industrial and Engineering Chemistry Research, 2018, 57, 11535.

14 R. R. Velarde, A. Grigotopoulos, N. Perret, M. Zanella, A. P. Katsoulidis, T. D. Manning, J. B. Claridge and M. J. Rosseinsky, Green Chemistry, 2017, 19, 1701.

15 M. A. Lilga, R. T. Hallen, T. A. Werpy, J. F. White, J. E. Holladay, J. R. Frye and A. H. Zacher.Patent U.S. Patent Application 2007/0287845, 2007.

16 M. S. Gyngazowa, L. Negahdar, L. C. Blumenthal and R. Palkovits, Chemical Engineering Science, 2017, 173, 455.

17 D. P. Duarte, R. Martinez and L. J. Hoyos, Industrial and Engineering Chemistry Research, 2016, 55, 54.

18 Y. Roman-Leshkov, C. J. Barret, Z. Y. Liu and J. A. Dumesic, Nature, 2007, 447, 982.

19 Y. Zhu, X. Kong, H. Zheng, G. Ding, Y. Zhu and Y.-W. Li, Catalysis Science and Technology, 2015, 5, 4208.

20 Y. Liu, M. M. Mellmer, D. M. Alonso and J. A. Dumesic, ChemSusChem, 2015, 8, 3983.

21 A. Yepez, A. Pineda, A. Garcia, A. A. Romero and R. Luque, Physical Chemistry Chemimcal Physics, 2013, 15, 12165.

22 Z. Zhang, C. Wang, X. Gou, H. Chen, K. Chen, X. Lu, P. Ouyang and J. Fu, Applied Catalysis A: General, 2019, 570, 245.

23 G. Bottari, A. J. Kumalaputri, K. K. Krawczyk, B. L. Feringa, H. J. Heeres and K. Bart, ChemSusChem Communications, 2015, 8, 1323.

24 L. B. McCusker, R. B. Von Dreele, D. E. Cox, D. Louer and P. Scardi, Journal of Applied Crystallography, 1999, 32, 36.

25 J. Rodriguez-Carvajal, Physica B: Condensed Matter, 1993, 192, 55.

26 M. S. S. Doniach, Journal of Physics C: Solid State Physics, 1970, 3, 285.

27 D. A. Shirley, Physical Review B, 1972, 5, 4709.

28 B. Seemala, C. M. Cai, C. E. Wyman and C. Christopher, ACS Catalysis, 2017, 76, 4070.

29 D. Hu, H. Hu, H. Zhou, G. Li, C. Chen, J. Zhang, Y. Yang, Y. Hu, Y. Zhang and L. Wang, Catalysis Science and Technology, 2018, 8, 6091.

30 S. Srivastava, G. C. Jadeja and J. Parikh, Journal of Molecular Catalysis A: Chemical, 2017, 426, 244.

31 T.B. Massalski and H.W. King, Acta Metallurgica, 1962, 10, 1171.

32 M. Brzezinska, P. Garcia-Munoz, A. M. Ruppert and N. Keller, Materials, 2018, 11, 2260.
33 Y. Liu, L. Zhong, Z. Peng, Y. Song and W. Chen, Journal of Materials Science, 2010, 45, 3791.

34 M. H. Kim, B. Lim, E. Lee and Y. Xia, Journal of Materials Chemistry, 2008, 18, 4069.

35 M. Wang, L. Jiang, E. Jung, E. J. Kim and S. K. Hahn, RSC Advances, 2015, 5, 87496-87503

36 X. Ma, H. Li, T. Liu, S. Du, W. Qiang, Y. Wang, S. Yin and T. Sato, Applied Catalysis B: Environmental, 2017, 201, 348.

37 C. Han, M. Yang, B. Weng and Y. Xu, Physical Chemistry Chemical Physics, 2014, 16, 16891.

38 M. Behrens, F. Studt, I. Kasatkin, S. Kuhl, M. Havecker, F. Ablid-Pedersen, S. Zander, F. Girsdies, P. Kurr, B.-L. Kniep, Tovar M., R. W. Fischer, J. K. Norskov and R. Schlogl, Science, 2012, 336, 893.

39 C. A. Galvan, J. Schumann, M. Behrens, J.L. Fierro, R. Schlog| and E. Frei, Applied Catalysis B: Environmental, 2016, 195, 104.

40 J. Agrell, M. Boutonnet, I. Melian-Cabrera i J. L. G. Fierro, Applied Catalysis A: General, 2003, 253, 201.

41 G. J. Millar, I. H. Holm, P. J. R. Uwins i J. Drennan, Journal Chemical Society, Faraday Transactions, 1998, 94, 593.

42 T. Shishido, M. Yamamoto, D. Li, Y. Tian, H. Morioka, M. Honda, T. Sano and K. Takehira, Applied Catalysis A: General, 2006, 303, 62.

43 D. Ji, W. Zhu, Z. Wang and G. Wang, Catalysis Communications, 2007, 8, 1891.

44 R. Yang, X. Yu, Y. Zhang, W. Li and N. Tsubaki, Fuel, 2008, 87, 443.

45 J. Agrell, H. Birgersson, M. Boutonnet, I. Melian-Cabrera, R.M. Navarro and J.L.G. Fierro, Journal of Catalysis, 2003, 219, 389-403.

46 D. Syomin and B. E. Koel, Surface Science, 2002, 498, 53.

47 A. G. Panov i J. J. Fripiat, Journal of Catalysis, 1998, 178, 188.

48 C. Barakat, P. Gravejat, O. Guaitella, F. Thevenet and A. Rousseau, Applied Catalysis B: Environmental, 2014, 147, 302.

49 A. Panov and J. J. Fripiat, Langmuir, 1998, 14, 3788.

50 Y. Okamoto, K. Fukino, T. Imanaka and S. Teranishi, Journal of Physical Chemistry, 1983, 87, 3747.

51 V. A. RogovV. F. Serebryakov, N. M. Dobrynkin and V. V. Popovskii, Reaction Kinetics Catalysis Letters, 1989, 40(2), 195-200.

52 J. Szanyi and M.T. Paffett, Catalysis Letters, 1997, 43, 37-44.

53 E.K. Poels and D.S. Brands, Applied Catalysis A: General, 2000, 83, 191.

54 J.-W. Jiang, C.-C. Tu, C.-H. Chen and Y.-C. Lin, ChemCatChem, 2018, 10, 5449.

55 B. Zhang, Y. Chen, J. Li, E. Pippel, H. Yang, Z. Gao and Y. Qin, ACS Catalysis, 2015, 5, 5567.

56 J. Gong, H. Yue, Y. Zhao, S. Zhao, L. Zhao, J. Lv, S. Wang and X. Ma, Journal of the American Chemical Society, 2012, 134, 13922.

57 H. Lei, R.F. Nie, G.Q. Wu and Z.Y. Hou, Fuel, 2015, 154, 161166.

58 A. Le Valant, C. Comminges, C. Tisseraud, C. Canaff, L. Pinard and Y. Pouilloux, Journal of Catalysis, 2015, 324, 41.

59 J.-D Grunwaldt, A.M Molenbroek, N.-Y Tops $\varnothing$ e, H Topsøe and B.S Clausen, Journal of Catalysis, 2000, 194, 452.

60 M.S. Spencer, Topics in Catalysis, 1999, 8, 259. 